\title{
Predictors of consistent condom use among secondary school male students in Mbonge subdivision of rural Cameroon
}

\author{
Elvis Enowbeyang Tarkang \\ HIV/AIDS Prevention Research Network, Cameroon, P.O. Box 36, Commonwealth Avenue, Kumba, Southwest region, Cameroon
}

\section{Email address:}

ebeyang1@yahoo.com

\section{To cite this article:}

Elvis Enowbeyang Tarkang. Predictors of Consistent Condom Use among Secondary School Male Students in Mbonge Subdivision of Rural Cameroon. Science Journal of Public Health. Vol. 1, No. 4, 2013, pp. 165-174. doi: 10.11648/j.sjph.20130104.11

\begin{abstract}
Correct and consistent condom use during sexual intercourse remains the most effective protection against sexual transmission of the human immunodeficiency virus/acquired immune deficiency syndrome (HIV/AIDS) for sexually active young adults, who are hardest hit by the HIV/AIDS pandemic. This study uses data from secondary school male students in Mbonge subdivision of rural Cameroon, to determine the most significant predictors of consistent condom use, using the main components of the Health Belief Model (HBM). A disproportional, stratified simple random sampling technique was used to obtain a representative sample of 210 male respondents. A cross-sectional correlational design was adopted, collecting data using a self-administered questionnaire. Data were analyzed using the statistical package for social sciences (SPSS) version 20 software program. Majority of the respondents, $65.8 \%$ reported having ever had sex, of whom only $30.5 \%$ reported using condoms consistently. Multinomial logistic regression analysis based on the HBM components showed that perceived susceptibility to HIV/AIDS ( $\mathrm{p}=0.007$; Pseudo R-square $=0.223$ ); perceived severity of HIV/AIDS $(\mathrm{p}=0.000$; Pseudo R-square $=0.382)$; perceived benefit of condom use $(\mathrm{p}=0.005$; Pseudo R-square $=0.144)$; perceived condom use self-efficacy $(\mathrm{p}=0.006$; Pseudo $\mathrm{R}$-square=0.223) and socio-demographic variables ( $\mathrm{p}=0.012$; Pseudo $\mathrm{R}$ square $=0.534$, were the most significant predictors of consistent condom use at the level $\mathrm{p}<0.05$. The findings suggest that AIDS education programs to increase condom use for males in rural Cameroon should emphasize these five components of the HBM concurrently. HIV/AIDS education messages that focus on barriers to condom use as a means of inducing and maintaining consistent condom use may be counterproductive.
\end{abstract}

Keywords: Consistent Condom Use, Rural Cameroon, Secondary School Male Students, Health Belief Model (HBM), HIV/AIDS

\section{Introduction}

Young adults represent the group at highest risk for HIV infection [1]. Many Cameroonian youths engage in risky sexual behaviors, such as having sex with casual partners or having unprotected intercourse, which may lead to sexually transmissible infections (STIs), including HIV/AIDS [2-4]. The estimated HIV/AIDS prevalence rate in Cameroon is 5.3\%[5].Juveniles in Cameroon aged 15-24 comprise 21.5\% of the total population and the estimated HIV/AIDS prevalence rate in this group was $9.1 \%$ in 2005 [6]. The HIV prevalence in the Southwest region of Cameroon is $11.0 \%$, which is above the national prevalence [7], and the prevalence among males in villages in rural Cameroon is also high, $5.2 \%$ [8].
These prevalence rates suggest that HIV prevention campaigns do not produce safer sexual behaviors, and that there is a built-up momentum of people living with HIV/AIDS. Young people entering their sexual prime should form a priority group for AIDS prevention because their behaviors will determine the future course of the HIV/AIDS pandemic in Cameroon.

In Cameroon, about $90 \%$ of HIV transmission occurs through heterosexual intercourse [9]. However, condoms remain the most effective protection against sexual transmission of HIV for sexually active young adults. Therefore, condom promotion has received considerable attention in the fight against the AIDS pandemic [10]. The HIV epidemic in Cameroon is driven by high-risk heterosexual practices such as low condom use, multiple concurrent partners or a high number of life time sexual 
partners.

Despite the risks of contracting HIV/AIDS among youth in Cameroon, consistent condom use has remained fairly low [11]. A study estimated condom use among youths at $31 \%$ for men [12], while another study put consistent condom use among sexually active adolescents in Cameroon at $25 \%$ [13].

The vulnerability of Cameroonian Youth to HIV infection necessitates the development of interventions that reduce sexual risk behaviors. To develop such interventions, knowledge of predictors of consistent condom use is indispensable.

Risk perception is a factor affecting condom use. Many studies in sub-Saharan African (SSA) have investigated predictors of condom use. A study on a community-based sample of young males in rural Ghana and a representative sample of young people in urban Cameroon found a strong positive association between perceived susceptibility to HIV/AIDS and a high level of condom use [14, 15]. Increased awareness of the severity of the AIDS epidemic also leads to increased condom use [15 16].

The perceived benefit of condom use and perceived selfefficacy for condom use have also been found to be important predictors of condom use [14, 15, 17, 18].

Others studies have reported perceived barriers to condom access and use as a significant predictor of condom use [19], while others in SSA have found sociodemographic factors to be important predictors of condom use [20].However, there are no studies on predictors of condom use among males in rural Cameroon. More than $51 \%$ of the population of Mbonge rural subdivision of the Southwest region of Cameroon is made up of males [21].

This study uses the main components of the Health Belief model (HBM): perceived susceptibility to HIV/AIDS, perceived severity of HIV/AIDS, perceived benefit of condom use, perceived barriers to condom use, perceived self-efficacy for condom use and sociodemographic factors, to determine the significant predictors of consistent condom use among secondary school male students in Mbonge subdivision of rural Cameroon.

It was hypothesized in this study that sexually active male students will use condoms consistently to prevent HIV/AIDS if they perceive themselves to be susceptible to HIV/AIDS, if they perceive HIV/AIDS to be severe in its nature and/or consequences, if they perceive condoms to be effective in preventing HIV/AIDS, if they perceive fewer barriers to condom use and if they believe in their ability to successfully use condoms [22].

\section{Data and Methods}

A cross-sectional, correlational design was adopted in this study.

The population refers to the entire set of cases about which the researcher would like to make generalizations and who meet the sampling criteria. In this study, the accessible population included all the senior secondary school students in Mbonge rural subdivision of Cameroon; that portion of the target population to which the researcher had reasonable access [23].

A disproportional, stratified, simple random sample was selected for this study. Probability sampling was used because it increased the likelihood that all the elements in the population would have an equal chance of being included in the sample [24]. The school attendance registers of the students were used as the sampling frame to select a sample of 210 grade 10 to grade 12 (Form five to upper sixth) male students from three senior secondary schools in Mbonge subdivision of Cameroon.

The data were collected during the first term of 2012 by means of a self-administered questionnaire comprising items regarding socio-demographic characteristics, and items relating to the major components of the HBM and condom use. A four-point Likert type scale was used to rate the responses, using the following response categories: strongly agree, agree, disagree and strongly disagree [25].

The questionnaire was pretested to clarify instructions, relevancy, usability and completion time, to refine and introduce modifications where necessary and to ascertain reliability and validity [26]. During the pre-test, 10 students who did not participate in the actual study completed the questionnaires. They required no assistance, understood the questions and needed approximately 15 minutes to complete the questionnaires.

The final questionnaires were administered to 210 male students from three senior secondary schools in Mbonge sub division of Cameroon during normal class periods with the permission of the principals and the co-operation of the teachers concerned. One research assistant was available to assist the students and to answer questions while they completed the questionnaires. The sample size of this study was determined using the formula for a single population proportion [27].

The reliability of the research instrument used for the study was tested using the coefficient alpha and by pretesting the questionnaires. The following types of validity were also established: face validity, content validity, construct validity and criterion-related validity. This was ensured by constructing items to represent the different components of the HBM, based on literature review. The questionnaires were also subjected to scrutiny by a statistician.

Permission to conduct this study was granted by the HIV/AIDS prevention Research Network, Cameroon (HIVPREC) an NGO for the prevention of HIV/AIDS through formalized education, working in the South West region of Cameroon, and the principals of the three participating schools. Participation was voluntary and informed written consent was obtained from each student and his parents/guardians prior to data collection. A questionnaire was handed to each student when he produced a signed consent form from a parent/guardian and from himself.

Anonymously completed questionnaires were kept in a 
separate container from the signed informed consent forms in order to maintain anonymity. Anonymity was also maintained by reporting the findings of the three schools combined and by not providing comparisons among the three schools. Confidentiality was maintained because only the researcher had access to the completed questionnaires, which were locked up. Subsequent to the acceptance of the research report, these would be destroyed.

Data were analyzed using SPSS version 20. Data were summarized by means of descriptive statistics including the frequency table. More advanced statistics included the chi square test at the 0.05 significance level and the multinomial logistic regression test.

\subsection{Model Specification and Estimation Procedure}

Multinomial logistic regression analysis was performed to examine the probability of using condoms consistently during sexual intercourse. Logistic regression does not require the predictors to be normally distributed, linearly related, or to have equal variances within each group. Logistic regression is especially useful when the distribution of responses on the dependent variable is expected to be non-linear with one or more of the independent variables $[28,29]$. The procedure gives rise to estimates of the likelihood of a certain event occurring, given a set of explanatory variables.

The HBM was tested drawing on its relevant theory and assumptions with regard to this study. The aim was to retain the assumptions of the model's application as much as possible and to assess the contributions of each component of the HBM and the various combinations of the components with regard to consistent condom use among senior secondary school male students in rural Cameroon.

The different modeling alternatives considered are:

- Maintaining the assumptions of component of the HBM.

- Integration of the components with high explanatory powers and significant levels (Integrated Value Mapping (IVM)).

Model estimation focused on mapping out the significant drivers of consistent condom use from a vector of consistently significant components suggested by the relevant theory underpinning the HBM.

During the regression analyses, items under each component of the HBM were considered together.

The dependent variable 'regularity of condom use' remained the same for all the modeling alternatives (the major components of the HBM, and the integrated value mapping (IVM)). For specific values of the independent variables (the various components of the HBM and the IVM), the estimated value of $P$ is the probability of the event that respondents mentioned that they used condoms consistently during sexual intercourse.

\section{Measures}

\subsection{Outcome (Dependent) Variable}

\subsubsection{Consistent Condom Use}

The outcome variable for this study is consistent condom use during sexual intercourse as reported by the male students. This measure was derived from the question:

"How often do you use a condom with a partner during sexual intercourse?" The response options were: ' 1 =always', ' $2=$ most of the time', ' $3=$ seldom' and ' $4=$ never.' This question was asked only to respondents who were sexually active.

\subsection{Explanatory (Independent) Variables}

- $\quad$ Perceived susceptibility to HIV: This was constructed from two questions, each considered separately: 'HIV/AIDS is a serious threat in Cameroon,' and 'A healthy looking person can be HIV positive'. The coefficient alpha for this 2-item scale was 0.418 . The response options were rated on a four-point Likert scale as ' $3=$ strongly agree', ' $2=$ agree', ' $1=$ disagree' and ' $0=$ strongly disagree'. 'Strongly agree' and 'agree' were coded as the index category.

- $\quad$ Perceived severity of HIV/AIDS: This measure was based on the degree of agreement with the following statements: 'HIV/AIDS is a disease like any other', 'Some traditional healers can cure AIDS', 'Some antibiotic can cure AIDS' and 'AntiRetroviral Therapy (ART) can cure AIDS'. The Cronbach's alpha for this 4-item scale was 0.474 . The response options were the same as for 'perceived susceptibility' and were coded in the same manner.

- $\quad$ Perceived Benefit Of Condom Use: This measure was based on the degree of agreement with the following statement: 'Correct and consistent use of condoms during sexual intercourse could prevent transmission of HIV/AIDS'. The response options were the same as for 'perceived severity' and were coded in the same manner.

- $\quad$ Perceived Condom Use Self-Efficacy: This measure was based on the degree of agreement with the following statements: 'I have confidence that I could refuse sex with my partner if he refuses to use condoms' and 'I feel confident that I can convince my partner(s) to use condoms during sexual intercourse'. This 2-item scale had a Cronbach's alpha of 0.572 . The response options were the same as for 'perceived benefit' and were coded in the same manner.

- $\quad$ Perceived Barriers To Condom Use: This measure was based on the degree of agreement with the following statements: 'Should a condom slip off during sexual intercourse it will land up in my stomach,' 'Latex condoms cause itching', 'I am 
allergic to lubricants used in condoms' and 'I feel embarrassed to ask my partner to use condoms'. The Cronbach's alpha for this 4-item scale was 0.499. The response options were the same as for 'perceived self-efficacy and were coded in same manner.

- Socio-Demographic Variables: The following socio-demographic variables were included in the study: age group, marital status, academic profile, house of residence, religious affiliation, and father's and mother's monthly incomes. Age was selfreported by respondents in years. Marital status was dichotomized as 'single' (index category) and 'married or cohabiting'. Academic profile was dichotomized as 'passed on merit' (index category) and 'promoted on trial or repeated'. House of residence was dichotomized as ' 5 rooms or more' (index category) and 'four rooms or less'. Religious affiliation was dichotomized as 'Christian' (index category) and 'others'. Father's and mother's monthly incomes were dichotomized as '200 000XAF and above' (index category) and 'less than $200000 X A F$ '.

- Sexual Experience: This was measured with the question: Have you ever had sexual intercourse with a female partner? With ' $1=$ yes' or ' $0=$ no' as response options. Condom use prevents sexual transmission of HIV only when used correctly and consistently.

\section{Results}

\subsection{Descriptive Statistics}

The descriptive statistics of the explanatory and dependent variables are shown in table 1 . Most of the respondents $(94.3 \% ; n=198)$ were $15-24$ years old. Most $(95.7 \% ; n=199)$ were single, and all were senior secondary school male learners. Of the respondents, $90.7 \%$ were Christians. Most of the respondents (77.6\%) passed their exams on merit. Most of their fathers' and mothers' monthly incomes were less than $200000 \mathrm{XAF}$ (that is less than US \$ 13.00 a day)(62.8\% and $78.7 \%$ ) respectively.
Table 1: Socio-demographic characteristics of male students

\begin{tabular}{|c|c|c|c|}
\hline \multicolumn{2}{|c|}{ Characteristics } & \multirow[t]{2}{*}{ Frequency } & \multirow[t]{2}{*}{ Percentage } \\
\hline$*$ & Age Group $(n=210)$ & & \\
\hline- & Less than 15 & 12 & 5.7 \\
\hline- & $15-24$ & 198 & 94.3 \\
\hline$*$ & Marital Status $(n=208)$ & & \\
\hline- & Single & 199 & 95.7 \\
\hline- & Married or cohabiting & 9 & 4.3 \\
\hline$*$ & $\begin{array}{l}\text { Academic profile } \\
(\mathrm{n}=\mathbf{2 1 0})\end{array}$ & & \\
\hline- & Passed on merit & 163 & 77.6 \\
\hline- & $\begin{array}{l}\text { Promoted on trial or } \\
\text { repeated }\end{array}$ & 47 & 22.4 \\
\hline$*$ & $\begin{array}{l}\text { Religious Affiliation } \\
(n=205)\end{array}$ & & \\
\hline- & Christian & 186 & 90.7 \\
\hline- & Others & 19 & 9.3 \\
\hline$*$ & $\begin{array}{l}\text { Father's monthly income } \\
(n=188)\end{array}$ & & \\
\hline- & 200 000XAF and above & 70 & 37.2 \\
\hline- & Less than $200000 \mathrm{XAF}$ & 118 & 62.8 \\
\hline$*$ & $\begin{array}{l}\text { Mother's monthly } \\
\text { income }(n=197)\end{array}$ & & \\
\hline- & 200 000XAF and above & 42 & 21.3 \\
\hline- & Less than $200000 \mathrm{XAF}$ & 155 & 78.7 \\
\hline
\end{tabular}

With respect to the various components of the HBM as depicted in table 2, perception of susceptibility to HIV/AIDS was not very high. Most respondents, 90.1\% perceived that a healthy looking person can be HIV positive, but as many as $34.0 \%$ perceived that HIV/AIDS is not a serious threat in Cameroon.

Perceived severity of HIV/AIDS was not high. As many as $20.8 \%$ perceived that traditional healers can cure AIDS; $20.6 \%$ perceived that ART can cure AIDS, although 58.7\% perceived that HIV/AIDS is a disease like any other.

The perceived effectiveness of using condoms to prevent HIV was quite high. Most respondents, $81.5 \%$ perceived that correct and consistent condom use during sex can prevent HIV.

The perceived barrier to condom access and use was not quite high. Most respondents, $56.3 \%$ perceived that latex condoms cause itching, $48.3 \%$ mentioned that they felt embarrassed to ask their partners to use condoms and $42.5 \%$ mentioned that they were allergic to lubricants used in condoms.

For perceived condom use self-efficacy, as many as $74.9 \%$ indicated that they have the confidence that they could refuse sex with their partners if they refuse to use condoms and $70.4 \%$ indicated that they felt confident that they can convince their partner(s) to use condoms during sexual intercourse. 
Table 2: Components of the HBM

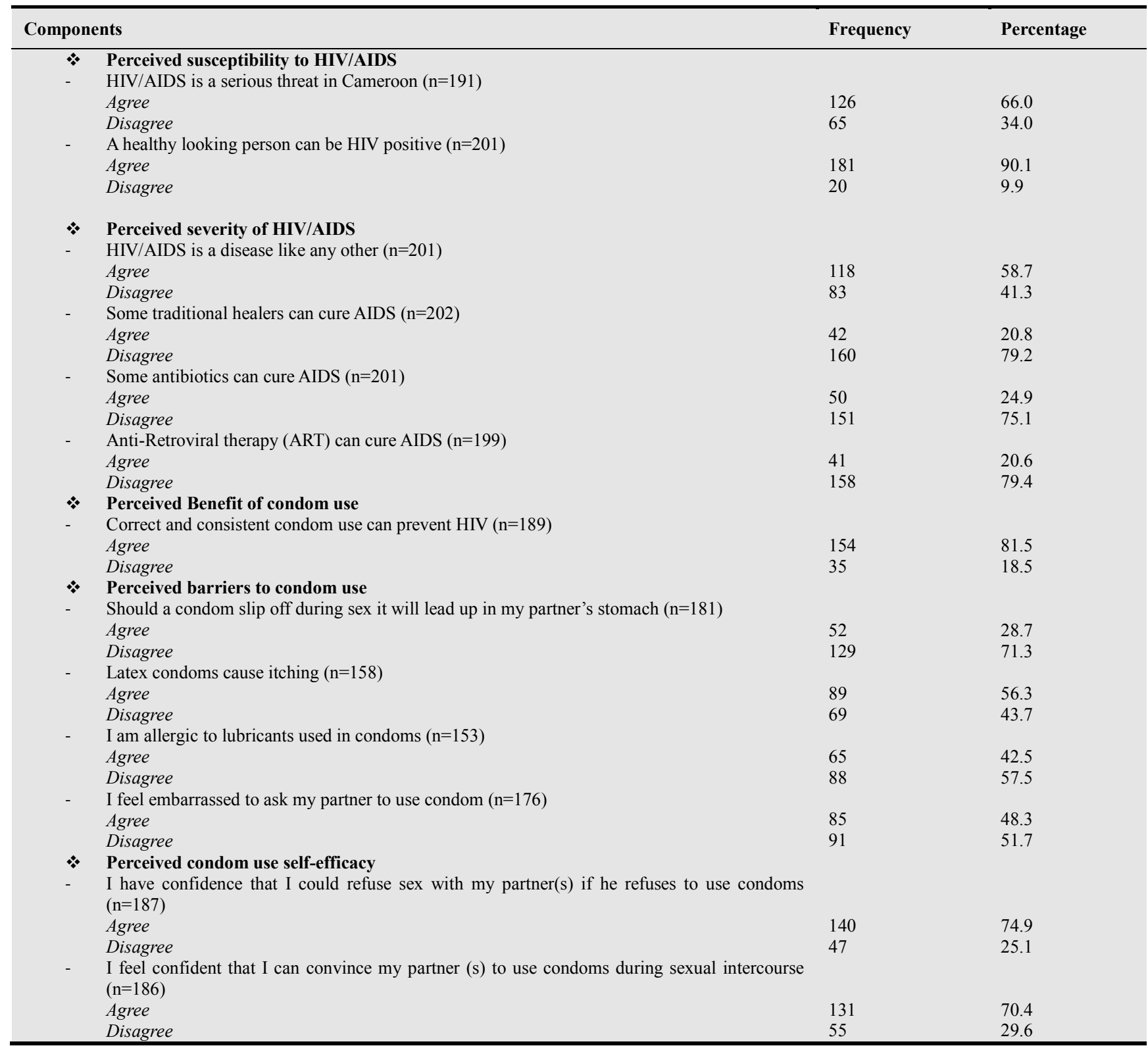

Although most of the respondents, $65.8 \%$ were sexually active, only $30.5 \%$ of these sexually active respondents were using condoms consistently (table 3 ).

Table 3: Regularity of condom use by male students

\begin{tabular}{clll}
\hline Variables & Frequency & Percentage \\
\hline * Sexual experience $(\mathrm{n}=191)$ & & \\
$-\quad$ Yes & $131 / 199$ & 65.8 \\
$-\quad$ No & 68 & 34.2 \\
& & \\
* & Regularity of condom use & \\
& (n=131) & \\
$-\quad$ Always & 40 & 30.5 \\
$-\quad$ Most of the time & 37 & 28.2 \\
$-\quad$ Seldom & 18 & 13.8 \\
$-\quad$ Never & 36 & 27.5 \\
\hline
\end{tabular}

\subsection{Predictors of Consistent Condom Use}

The level of significance of the various components of the HBM is explained by the P-value of the Chi-square statistics. If this P-values are discussed at alpha $=0.05$, then perceived susceptibility to HIV/AIDS $(\mathrm{P}=0.007)$; perceived severity of HIV/AIDS $(\mathrm{P}=0.000)$; perceived benefit of condom use $(\mathrm{P}=0.005)$; perceived condom use self-efficacy $(\mathrm{P}=0.006)$ and the socio-demographic variables $(\mathrm{P}=0.012)$ have high significance levels (table 4$)$. The IVM for the entire HBM remained very unstable $(\mathrm{P}=0.062)$; while the IVM for perceived susceptibility to HIV/AIDS, perceived severity of HIV/AIDS, perceived benefit of condom use, perceived condom use self-efficacy and the socio demographic factors remained very stable $(\mathrm{P}=0.000)$.

The significance levels of the various HBM components 
followed the same patterns as their explanatory powers with regard to predicting consistent condom use, with socio-demographic factors having the highest explanatory power of $53.4 \%$ (Pseudo R-square $=0.534$ ), followed by perceived severity of HIV/AIDS of $38.2 \%$ (pseudo Rsquare $=0.382$ ), perceived susceptibility to HIV/AIDS, $22.3 \%$ (pseudo R-square $=0.223$ ), then perceived condom use self-efficacy, 22.3\% (pseudo R-square=0.223) and perceived benefit of condom use, 14.4\% (pseudo Rsquare $=0.144$ ).

The IVM for perceived susceptibility to HIV/AIDS, perceived severity of HIV/AIDS, perceived benefit of condom use, perceived condom use self-efficacy and the socio-demographic factors had the strongest explanatory power, $95.5 \%$ (pseudo R-square $=0.955$ ).

Table 4: multinomial logistic regressions between explanatory variables and consistent condom use

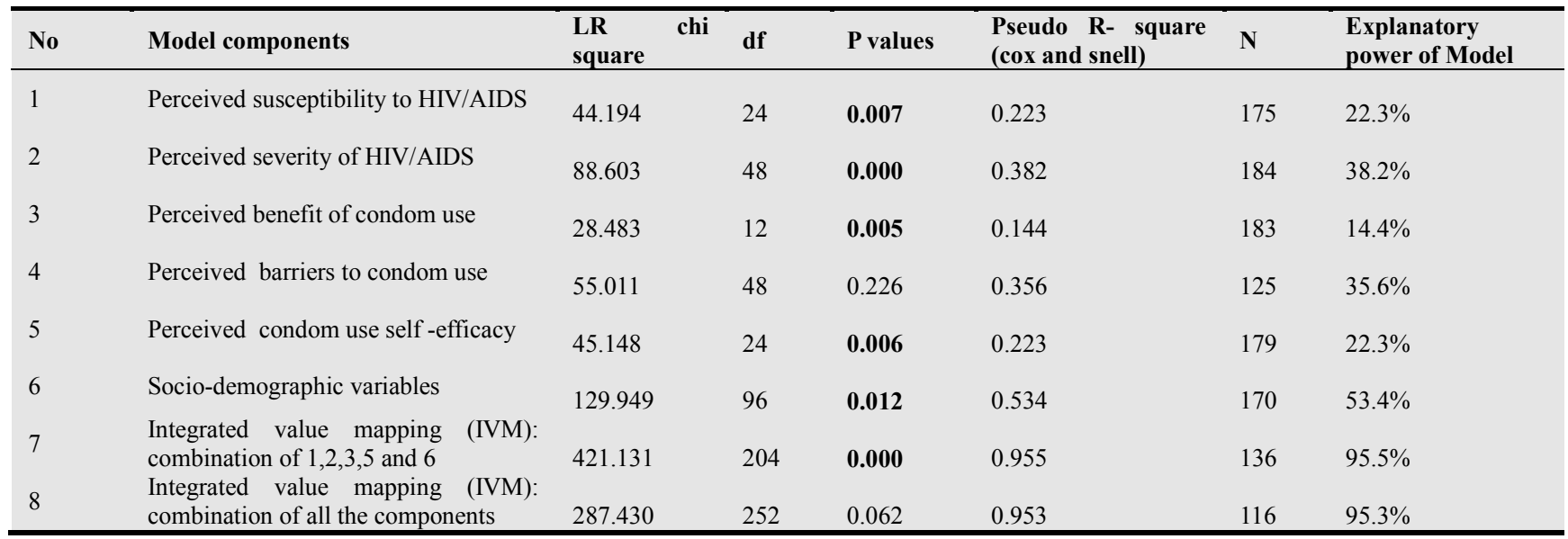

$\mathrm{df}=\mathrm{degree}$ of freedom

The likelihood ratio test (table 5) summarizes the relationship between the predictors and the outcome variable for the IVM (components of the HBM with satisfactory explanatory powers and high significance (perceived susceptibility to HIV/AIDS, perceived severity of HIV/AIDS, perceived benefit of condom use, perceived condom use self-efficacy and the socio-demographic factors)).

Table 5: Components of the IVM-Likelihood ratio tests

\begin{tabular}{|c|c|c|c|c|}
\hline Effect & -2 Log Likelihood of Reduced Model & Chi-Square & df & Sig. \\
\hline \multicolumn{5}{|l|}{ Perceived susceptibility to HIV } \\
\hline HIV/AIDS is a serious threat in Cameroon & 135.766 & 29.047 & 12 & 0.004 \\
\hline \multicolumn{5}{|l|}{ Perceived severity of HIV/AIDS } \\
\hline HIV/AIDS is a disease like any other & 303.939 & 22.403 & 12 & $\mathbf{0 . 0 3 3}$ \\
\hline Some traditional healers can cure HIV/AIDS & 302.804 & 21.328 & 12 & 0.046 \\
\hline Anti-Retroviral Therapy (ART) can cure AIDS & 312.581 & 31.046 & 12 & 0.002 \\
\hline \multicolumn{5}{|l|}{ Perceived benefit of condom use } \\
\hline $\begin{array}{l}\text { Correct and consistent condom use during sexual } \\
\text { intercourse could prevent transmission of HIV/AIDS }\end{array}$ & 76.146 & 28.483 & 12 & 0.005 \\
\hline \multicolumn{5}{|l|}{ Perceived condom use self-efficacy } \\
\hline $\begin{array}{l}\text { I feel confident that I can convince my partner(s) to use } \\
\text { condoms during sex }\end{array}$ & 170.626 & 34.003 & 12 & 0.001 \\
\hline \multicolumn{5}{|l|}{ Socio-demographic variables } \\
\hline Age & 388.572 & 59.832 & 40 & 0.023 \\
\hline
\end{tabular}

$\mathrm{df}=$ degree of freedom

Male students who perceived that HIV/AIDS is a serious threat in Cameroon, who perceived that correct and consistent condom use during sexual intercourse can prevent the transmission of HIV/AIDS, who felt confident that they can convince their partners to use condoms during sexual intercourse, and who were of the older age group were more likely to consistently use condoms during sexual intercourse. On the other hand, students who perceived that 
HIV/AIDS is a disease like any other, who perceived that some traditional healers can cure HIV/AIDS, and who perceived that ART can cure AIDS, were less likely to use condoms consistently during sexual intercourse.

\section{Discussion}

Majority of the male students were among the age group hardest hit by HIV/AIDS [30]. Single persons are predisposed to sexual temptations which might increase their vulnerability to STIs and HIV/AIDS [31].Marital status is one of the demographic variables which predispose one to take preventive action against HIV/AIDS infection due to repeated exposure to unprotected sexual intercourse among unmarried adolescents which increases their risk of HIV/AIDS infection. These findings, especially the high percentage of unmarried respondents were to be expected, as all the respondents were still students, and most were still living with their parents, hence were single.

Behavioral, physiological and socio cultural factors, such as early sexual initiation, multiple sexual partners, non-use or inconsistent use of condoms and substance abuse, make young males more vulnerable to HIV/AIDS than adults [32]. Compounding these behavioral factors is the fact that young people have to overcome significant obstacles to obtain the information and care they need to have safe sexual relationships.

This study examined the predictors of consistent condom use among secondary school male students in Mbonge rural area of Cameroon, using the HBM.

The HBM has the premise that individuals will take action to prevent a health problem (HIV/AIDS) if they regard themselves to be susceptible to the condition, if they perceive the problem to be severe in its nature and/or consequences, if they perceive that the action (consistent condom use) will benefit them by reducing their susceptibility, if they perceive few barriers to taking that action (consistent condom use) and if they believe in their ability to successfully take the recommend action (consistent condom use) to prevent HIV/AIDS [33, 34].The concepts and relationships within the HBM work synergistically to create a greater understanding to explain and predict consistent condom use to prevent HIV/AIDS.

In accordance with other reports [14-18, 35], this study identified perceived susceptibility to HIV/AIDS, perceived severity of HIV/AIDS, perceived benefit of condom use, perceived condom use self-efficacy and socio-demographic factors as significant predictors of consistent condom use among male students in Mbonge subdivision of rural Cameroon.

Furthermore, in contrast to other report [19] there was no significant association between perceived barrier to condom use and consistent condom use.

Perceived susceptibility refers to an individual's estimated probability of encountering a specific health problem, in this case, HIV/AIDS. The degree of perceived susceptibility to HIV seems to affect individuals' actual control in using condoms consistently during sex [36]. Rosenstock (1990) who developed the HBM suggests that preventive action is more likely among those who feel vulnerable to a disease [37]. This study revealed that male students may not be motivated to use condoms consistently during sex when they fail to recognize their personal susceptibility to HIV/AIDS. The perception by some students that HIV/AIDS is not a serious threat in Cameroon revealed some misunderstanding and inadequate knowledge of HIV/AIDS which could decrease their perceived susceptibility to HIV/AIDS, and in turn increase their risk of contracting HIV/AIDS by not using condoms consistently.

Perceived severity refers to one's beliefs of how serious a condition and its consequences are [38]. When a student recognizes his susceptibility to HIV/AIDS, it does not necessarily motivate him to take the necessary preventive actions unless he realizes that getting the condition would have serious physical and social implications. It is when he realizes the magnitude of the negative consequences of HIV/AIDS, that he could take the necessary actions to avoid these negative consequences. In this study, the students who perceived that HIV/AIDS is a disease like any other, who perceived that some traditional healers can cure AIDS, and who perceived that ART can cure AIDS might not realize the need to use condoms consistently during sexual intercourse to prevent HIV/AIDS transmission.

Male students must perceive HIV/AIDS as a serious infection that has severe consequences and implications on their physical and social lives, before they would adopt preventative actions (such as consistent condom use) to prevent HIV/AIDS infection. The misconceptions regarding ART could lead learners to unsafe sexual practices, such as having unprotected sex with an HIV positive person. Art does not cure AIDS. ART aims to maximize the life expectancy of HIV positive people. Adherence to ART results in a decreased viral load, morbidity, mortality and increased in CD4 lymphocyte counts [39]. There is presently no cure for HIV/AIDS, so no traditional healer can claim to have a cure for HIV/AIDS. Such misconceptions could give rise to risky sexual behaviors among learners, such as unprotected sexual intercourse, with the belief that if they contract HIV/AIDS as a result of such risky sexual practices, they could be cured.

Students who lacked confidence in their ability to purchase condoms and negotiate their use might have a higher likelihood of engaging in unprotected intercourse. According to the HBM, students who perceived themselves to be susceptible to HIV/AIDS need to have the confidence that they can use condoms, before they could use them correctly and consistently to prevent HIV/AIDS. Perceived self-efficacy for condom use is one of several determinants of HIV sexual risk reduction and reproductive health. In this study, only $70.4 \%$ of the students felt confident that they can convince their partners to use condoms during sexual intercourse. 
We observed in this study that having self-efficacy in terms of having the confidence to convince one's partners to use condom during sexual intercourse, increases a male learner's ability to consistently use condoms during sexual intercourse to prevent HIV/AIDS. Bandura (1994) suggests self-efficacy to be the most powerful tool to increase condom use among males [40]. Therefore an important consideration in promoting condom use is the need to provide men with condom negotiation skills.

Adolescents, who lack perception of the effectiveness of condom use to prevent HIV/AIDS, might be less likely to use them consistently during sexual intercourse to prevent transmission of HIV/AIDS. In addition to the perception of the effectiveness of condom use to prevent HIV/AIDS, youths need to know how to use condoms effectively.

The five components of the HBM with high significance (perceived susceptibility to HIV/AIDS, perceived severity of HIV/AIDS, perceived benefit of condom use, perceived condom use self-efficacy and socio-demographic factors) should be given more priority than perceived barrier to condom use. This result implies that male students were not actually aware of the presence and severity (threat) of HIV/AIDS in their environment. Awareness of the benefit of condom use to prevent HIV/AIDS was also a major priority within the frame work of the HBM (perceived benefit of condom use and perceived condom use selfefficacy) as explained by their high significance and explanatory powers, unlike barriers to condom use. Male students were aware of the benefit of condom use to prevent HIV, and their self-efficacy for condom use was low. But they were not putting such knowledge on the benefit of condom use into practice by using condoms consistently during sexual intercourse to prevent HIV/AIDS transmission. HIV/AIDS prevention programs should also aim at increasing young men's self-efficacy that they can use condoms consistently.

The focus as depicted from the result of this study should be on perceived threat of HIV/AIDS, perceived benefit of condom use, perceived condom self-efficacy and sociodemographic factors. These components of the HBM, acting in synergy predict consistent condom use to prevent HIV/AIDS better than the other component (perceived barrier to condom use).

Our findings suggest that AIDS prevention programs to increase condom use for males in rural Cameroon should emphasize these five components of the HBM concurrently. HIV/AIDS education messages that focus on barrier to condom use as a means of inducing consistent condom use among males in rural Cameroon may be counterproductive, as shown in the analyses.

\section{Conclusion}

The overall impression is that the study has justified the $\mathrm{HBM}$ as a useful model in predicting consistent condom use to prevent HIV/AIDS among male students in rural Cameroon. The hypothesis that male students will use condoms consistently to prevent HIV/AIDS if they perceive themselves to be susceptible to HIV/AIDS, if they perceive HIV/AIDS to be severe in its nature and/or consequences, if they perceive condoms to be effective in preventing HIV/AIDS, if they perceive fewer barriers to condom use and if they believe in their ability to successfully use condoms, is supported by the research findings using the multinomial logistic regression model to establish statistically those components of the HBM (as defined by the items included in the self-administered questionnaire) with the highest explanatory powers and significance in predicting consistent condom use (perceived susceptibility to HIV/AIDS, perceived severity of HIV/AIDS, perceived benefit of condom use, perceived condom use self-efficacy and socio-demographic factors).

\section{Limitation}

The data collection took place in predominantly Christian areas of Cameroon. Different results may be obtained if data is collected from predominantly Muslim students. In addition, because most of the items in the questionnaire elicit self-reported information on sensitive issues such as condom use and HIV/AIDS, the respondents might have been bias in responding to these items. However assurance of confidentiality and anonymity might have minimized this problem. The sample size was small, and consequently the results of the study may not be generalized to the entire country. Increasing the sample size will provide a larger variety of respondents, which may result in the findings being generalized.

\section{Acknowledgements}

None

\section{Competing interests}

The author declares that he has no competing interests.

\section{References}

[1] UNAIDS, Report on the global HIV/AIDS Epidemic, Geneva, Switzerland, 2002.

[2] J. L. Arcand, and E. D. Wouabe, Teacher training and HIV/AIDS prevention in West Africa: Regression discontinuity design evidence from the Cameroon, Health Economics,vol. 19, pp. 36-54, 2010.

[3] J. J. Mosoko, I. B. Macauley, A. B. C. Zoungkanyi, A. Bella, and S. Koulla-Shiro, Human Immunodeficiency Virus infection and associated factors among specific population subgroups in Cameroon, AIDS and Behavior,vol.13, pp.277$287,2009$.

[4] E. J. Kongnyuy, V. Soskolne, and B, Adler, Hormonal contraception, Sexual behaviour and HIV prevalence among women in Cameroon, BMC Women's Health, vol. 8, pp.19, 2008. 
[5] UNAIDS, Report on the global AIDS Epidemic, Geneva, Switzerland, 2010.

[6] UNFPA, Country profiles for population and reproductive health: policy developments and indicators, Cameroon $\quad$ pp .26-27, 2005. From: http://www.unfpa.org/upload/lib_pub_file/524_filename_co untry_profiles_2005.pdf

[7] UNAIDS, Annex 2: HIV and AIDS estimates and data, Geneva, pp. 506-507, 2005.

[8] P. Nyambi, L. Zekeng, H. Kenfack, M. Tongo, A. Nanfack, I. Nkombe, F. Ndonko, J. Shang, S. Burda, H. Mbah, L. Agyingi, P. Zhong, A. Nadas, S. Zolla-Pozner, and M. Marmor, HIV infection in rural villages in Cameroon, J AcqImmunDefSyndr, vol. 31(5), pp. 506-13, 2002.

[9] L. Fonjong, Fostering women's participation in development through Non-governmental efforts in Cameroon, Geographical Journal of the Royal Geographical Society, vol. 167(3), pp. 223-234, 2001.

[10] J. Neukom, and L. Ashford, Changing youth behaviour through social marketing. Program experience and research findings from Cameroon, Madagascar, and Rwanda, Washington, DC: PRB \& PSI, 2003.

[11] R. Van Rossem, and D. Meekers, An evaluation of the effectiveness of targeted social marketing to promote adolescent and young adult reproductive health in Cameroon, AIDS Education and Prevention, vol. 12, pp. 383-404, 2000.

[12] UNICEF, Enquête ā indicateurs multiples (MICS) au Cameroon 2000 Yaoundé: Ministere de L'Economicet des Finances, Gouvernement du Cameroun, 2001.

[13] M. Rwenge, Sexual risk behaviours among young people in Bamenda, Cameroon, International Family Planning Perspectives,vol. 26(3), pp. 118-123 \& 30, 2000.

[14] W. K. Adih, and C. S. Alexander, Determinants of condom use to prevent HIV infection among Youth in Ghana, Journal of Adolescent Health, vol. 24(1), pp. 63-72, 1999.

[15] D. Meekers, and M. Klein, Determinants of condom use among young people in Urban Cameroon, Studies in Family Planning, vol. 33(4), pp. 335-346, 2002.

[16] J. Lugalla, M. Emmelin, A. Mutembei, M. Sima, G. Kwesigabo, J. Killewo, and L. Dahlgren, Social, cultural and sexual behavioral determinants of observed decline in HIV infection trands: Lessons from the Kagera Region, Tazania, Social Science \& Medicine, vol. 59, pp. 185-198, 2004.

[17] S. Abdool Karim, Q. Abdool Karim, E. Preston-Whyte, and N. Sankar, Reasons for lack of condom use among high school students, South African Medical Journal, vol. 82, pp.107-110, 1992 .

[18] P. Sheeran, C. Abraham, and S. Orbell, Psychosocial correlates of heterosexual condom use: A meta-analysis, Psychological Bulletin, vol. 125, pp. 90-132, 1999.

[19] C. U. Edem, and S. M. Harvey, Use of Health Belief Model to predict condom use among university students in Nigeria, Int. Quart. Comm. Hlth. Educ,vol.15, pp. 3-14, 1995.

[20] K. Basen-Engquist, Psychosocial predictors of "safer sex" behaviours in young adults, AIDS Educ. P,vol.4, pp. 120134, 1992.

[21] Bureau Central des Recensements et des Etudes de Population, Livre "Rapport de Presentation", Cameroon, 2010.

[22] A.E. Stout, Prenatal care for low income women and the Health Belief Model: a new beginning, Journal of Community Health Nursing, vol. 4(3), pp. 169-180, 1997.

[23] N. Burns, and S.K. Grove, The practice of nursing research: conduct, critique and utilization; $5^{\text {th }}$ edition. St Louis: ELSEVIER, 2005.

[24] H. I. Brink, C. Van der Walt, and G. Van Rensburg, Fundamentals of research methodology for health care professionals; $2^{\text {nd }}$ edition. Cape Town: Juta, 2006.

[25] E. Babbie, The basics of social research; $3^{\text {rd }}$ edition. Toronto: Thomson Wadsworth, 2005.

[26] C. Bless, and C. Higson-Smith, Fundamentals of social research methods: an African perspective. $3^{\text {rd }}$ edition. JUTA, 2000 .

[27] S. L. Levy, and S. Lemeshow, Sampling of populations : Methodsand applications, 3rd edition, New York: John Wiley\& Sons, 1999.

[28] A. Agresti, An Introduction to categorical Data Analysis, New York: Wiley, 2007.

[29] D. W. Hosmer, and S. Lemeshow, Applied Logistic Regression, New York: Wiley and Sons Inc, 2000.

[30] USAID, Country health statistical report, Cameroon, Masimax Resource Inc, John Snow Inc, ORC Macro \& Insight Systems Corporation, Washington DC, 2008.

[31] W. K. Nahamya, and C. B. Elangwe, Susceptibility and vulnerability to HIV/AIDS among the fishing communities in Uganda: a case of Lake Kioga. A paper presented to the international conference on HIV/AIDS and food and nutrition security, Hilton Hotel, Durban, 2005. From http://www.ifpri.org/events/conferences/2005/durban/papers /nahamyaWP.pdf. (Accessed on 15/10/2011).

[32] The Alan Guttmacher Institute,Risk and protection: youth and HIV/AIDS in Sub-Saharan Africa. New York and Washington: The Alan Guttmacher Institute, 2004.

[33] N. Pender, C. Murdaugh, M. A. Parsons, Individual models to promote health behaviour. In M, Connon, D Macknight, $\mathrm{K}$, Mortimer \& S, Wrocklage (eds), Health promotion in Nursing Practice, pp. 35-66. Now York: Pearson, 2011.

[34] Bartholomew LK, Parcel G, KOK G, Gottlieb NH. Behavior oriented theories used in health promotion. In J, Allegrante, K, Mcleroy (eds). Planning Health Promotion Programs. 2006; 81-135. San Francisco: Jossey-Bass.

[35] E. E. Tarkang, Factors associated with consistent condom use among senior secondary school female learners in Mbonge subdivision of rural Cameroon, Journal of AIDS and HIV Research, vol. 5(6), pp. 214-223, 2013.

[36] L. Bernardi, Determinants of individual AIDS risk perception: knowledge, behavioural control, and social influence. MPIDR WORKING PAPER WP 2002-029, July 2002: Max-Planck Institute for Demographic Research. From: http://www.demogr.mpg.de (accessed on 24/10/2006). 
[37] I. M. Rosenstock, The Health Belief Model: explaining health behavior through expectancies: in glanz, Lewis \& Rimer (eds): health behavior and health education. San Francisco: Jossey - Bass Publishers, 1990.

[38] G. Groenewold, B. Bruijn, and R. Bilsborrow, Migration of the Health Belief Model (HBM): effects of psychology and migrant network characteristics on emigration intentions on five countries in West Africa and the Mediterranean region. Population association of America 2006 annual meeting.
[39] K. N. Simpson, D. Whipper-Lewis, and P. Mazyck, Economic access to highly active Anti-Retroviral Therapy (HAART) and adherence to treatment guidelines for African American medical enrollees with AIDS in South Carolina. AHRQ. Exceed project 2, 2006.

[40] A. Bandura, Health promotion from the perspective of social cognitive theory. In P. Norman, C. Abraham, \& M, Conner, (Ed), Understanding and changing health behaviour: from health beliefs to self-regulation. (PP.299-339) Amsterdam: Hardwood Academic, 1994. 